Evidence Updates

\title{
Prevalence and change detection of child growth failure phenomena among under-5 children: A comparative scrutiny from NFHS-4 and NFHS-5 in West Bengal, India
}

\author{
Partha Das ${ }^{\mathrm{a}}$, Ranjan Roy ${ }^{\mathrm{b}}$, Tanu Das ${ }^{\mathrm{a}}$, Tamal Basu Roy ${ }^{\mathrm{c}, *}$ \\ a Department of Geography; Raiganj University, Uttar Dinajpur, West Bengal, 733134, India \\ ${ }^{\mathrm{b}}$ Department of Geography and Applied Geography, University of North Bengal, West Bengal, India \\ ${ }^{\mathrm{c}}$ Department of Geography, Raiganj University, Raiganj, Uttar Dinajpur, West Bengal, India
}

\section{A R T I C L E I N F O}

\section{Keywords:}

Child growth failure

Stunting

Wasting

Underweight

NFHS-5

\begin{abstract}
A B S T R A C T
Background: Nowadays child growth failure phenomena are an enduring public health concern in lower \& middle-income countries like India. West Bengal is a northeastern state of India where child growth failure incidents are predominately relevant which can cause morbidity and mortality among under-5 children.

Methods: The district-level data of child growth failure indices were extracted from the district fact sheets of West Bengal state, published by NFHS, India. This study is based upon two-time frames of the NFHS (NFHS-4 \& NFHS5) series. District wise change detection of child growth failure indices was estimated by differencing the last series prevalence from the previous series prevalence and spatial distribution of current child growth failure indices has been shown through thematic mapping.

Result: Results revealed that the prevalence of stunted children is increased across 7 districts whereas wasted from 10 districts and underweight from 9 districts of West Bengal. As per data reported in the NFHS-5 fact sheet, there are still several districts in West Bengal where the prevalence of stunting, wasted, and underweight children have remained more than $30 \%$.

Conclusion: District level direct public intervention programs to enhance parent's education, their household's standard of living, and childhood health care facilities should be given more priority to combat the children's growth failure problem in high priority districts. This study will be beneficial for policymakers and health workers to understand the dynamic nature of prevalence and changes of child growth failure indices across the districts in West Bengal.
\end{abstract}

\section{Introduction}

Malnutrition or growth failure is a horrendous public health issue, and it continues to be a major child health problem nationwide, especially in south-east Asia and Sub-Saharan Africa. It is a pathological abnormality caused by imbalanced, inadequate or overconsumption of the macronutrients (carbohydrates, protein and fats) that supplies dietary energy and the micronutrients (vitamins and minerals) that are necessary for physical as well as cognitive development. The health consequences of an extended state of malnutrition among children comprise delayed physical growth, weaken cognitive and motor development, shrinking Intellectual Quotient (IQ) level, cognitive performance, diminished psychosocial development and reduce body size in adulthood that may decrease the economic productivity of a country. ${ }^{1-4}$ Malnutrition is broadly classified into over nutrition (obesity and overweight) and under nutrition (stunting, wasting and underweight) condition on any human being regardless of age, sex, caste, class etc. while child growth failure is one of the major adverse outcomes of under nutrition among children under 5 years of age. ${ }^{5,6}$ At present many lower and middle-income countries are suffering from child growth failure phenomena that can cause severe ill-health conditions among children which may lead them to morbidities and mortality conditions and India is not an exception. ${ }^{1,7-10}$ Close to 156 million children under 5 years of age are suffering from stunting, 50 million are suffering from

\footnotetext{
Abbreviations: NFHS, National Family Health Survey; IQ, Intellectual Quotient; RCH, Reproductive and Child Health.

* Corresponding author.

E-mail addresses: parthadas7852@gmail.com (P. Das), royranjangeo@gmail.com (R. Roy), tanudas.04321@gmail.com (T. Das), raiganjgeo@gmail.com (T.B. Roy).
} 
wasting and 93 million are underweight worldwide. $^{11}$ Despite well-concerted efforts nationally and globally, the prevalence of child growth failure phenomena remained high in India. Evidence from the UNICEF report suggests that the prevalence of stunting children has decreased from $52 \%$ in $1992-93$ to $38 \%$ in $2015-16$ but the proportion of wasted children had increased to $21 \%$ from $17 \%$ during this period. Evidence also suggests that India contribute $40 \%$ of the global share of stunted children. ${ }^{12}$ Most of the previous studies from India had examined the prevalence of child growth failure phenomena and identified social, economic and demographic correlates of child growth failure indices at household and individual levels. However, India contributes a large number of states which exhibits abundant variation in socio-economic, demographic and cultural indicators. And very little is known about the spatial heterogeneity of child growth failure indices at a micro-scale i.e., at the district level. West Bengal is a north-eastern state of India where the occurrences of child growth failure phenomena are predominately relevant which can cause childhood diseases, morbidity and mortality among under- 5 children. ${ }^{13}$ Latest round of the National Family Health Survey (NFHS-5) reported that $34 \%$ of children age less than 5 years are suffering from stunting or they are too short for their age; $20 \%$ of children are too thin for their height (wasted) and $32 \%$ under 5 children are underweight. Surprising thing is that the prevalence of wasted and underweight children remained constant between NFHS-4 (2015-2016) and NFHS-5 (2019-2020) rounds. The continuing trend on high levels of under nutrition is still a major problem in West Bengal. ${ }^{13}$ Past epidemiological estimations from various developing countries have identified diverse factors associated with child growth failure phenomena, including household poverty, food insecurity, rural residential place, maternal depression, low parental education and suboptimal infant feeding. ${ }^{14-26}$ Child growth failure or under nutrition condition is also positively and significantly associated with the low level of maternal autonomy within the family. ${ }^{27}$ One study from Ethiopia concluded that high food prices and low maternal nutrition knowledge are two key determinants of child growth faltering. ${ }^{28}$ A study from India based on large scale NFHS data interpreted that children born to adolescents mothers were at more risk of being undernourished. Adolescent pregnancy is related to child growth faltering occurrence through poor maternal nutritional status, lower education, less health care service access, inadequate complementary feeding practices, and poor living conditions. ${ }^{29}$ As above said, level of child growth failure incidents remains higher in West Bengal and its overtime declining trend has been slower as compared to the economically identical states. Nowadays inter-districts variation in the magnitude of child growth failure incidents across the state is a serious matter of concern because there have 13 districts in West Bengal where at least one child growth failure measurement is increased in 2019-2020 from 2015 to 2016, while the goal 2 of Sustainable Development Goals (SDGs) aimed to end hunger and all forms of malnutrition by 2030. Inter-district variation in the magnitude of child growth failure incidents across the state possibly resulting from socio-economic inequalities, reproductive and child health care inequalities and may be due to differences in the physical environment. One study conducted in west Bengal to identify the position of the districts of West Bengal in respect of the overall Reproductive and Child Health ( $\mathrm{RCH}$ ) care status based on 7 maternal and child health indicators and result revealed that some districts like Uttar Dinajpur, Maldha, Murshidabad and Puruliya have been remaining backward. ${ }^{30}$ In several district level \& community level estimations author/authors drawn their inferences that disparity exists among different districts or communities of West Bengal in subject to literacy, poverty, unemployment, women's age at marriage etc. and that are significantly linked with child growth failure phenomena as already proved. ${ }^{31-34}$ To the best of our knowledge, none of the studies have identified major achievements and shortcomings on progress made on key indicators related to the nutritional status of Under-5 children in the last 5 years (2015-2016 to 2019-2020) by making a comparative analysis from district level NFHS- 4 fact sheets and NFHS- 5 fact sheets of West Bengal state. In this context the main purpose of this study is to find out the changes of child growth failure indices with the help of anthropometric measurements of Under 5 children in different districts of West Bengal and this study also shows the current (2019-2020) prevalence of child growth failure indices (stunting, wasting, and underweight) across the districts of West Bengal. This study will be beneficial for policy makers and health workers to understand the dynamic nature of prevalence and changes of child growth failure indices across the districts in West Bengal.

\section{Materials \& methods}

\subsection{Data source}

This study used data of child growth failure indices from district level fact sheets of west Bengal state published by the National Family Health Survey (NFHS), India. This study was carried out based upon two-time frames of the NFHS (NFHS-4, 2015-2016 \& NFHS-5, 2019-2020) series. The fact sheets are publicly available on the respective website (http://rchiips.org/nfhs/) and one can access the data set without any prior request. All the NFHS surveys have been conducted under the stewardship of the Ministry of Health and Family Welfare (MoHFW), Government of India. MoHFW designated the International Institute for Population Science (IIPS), Mumbai, as the nodal agency for the survey. The survey included women who were usual residents in the sample households or who were visitors who had stayed in the sample households the night before the interview. Information was collected on height, weight and other anthropometric measurements of ever-married women aged 15-49 years and children born to those women in the 5 years preceding the survey. Because of almost similar content in both the NFHS 4th \& NFHS 5th round, it is possible to compare child growth failure indices over time across the districts of West Bengal, India.

\subsection{Child anthropometry}

The main outcomes of interest for the present study are children's growth failure indices, classified as stunting, wasting and underweight status of Under- 5 children. The corresponding score, i.e., height-for-age Z-score (HAZ), weight-for-height Z-score (WHZ) and weight-for-age Zscore (WAZ) were measured from children's height/length, weight and age data which has been given in the respective NFHS dataset. NFHS permit their surveyor to collect anthropometric information about children's height and weight measurement and also give permission to the statistical evaluation team for estimating (Z-score) the current nutritional status of under- 5 children, India. Each of these indices provides different information about children's growth and body compassion for assessing the nutritional status of the children. Children whose HAZ is below minus two standard deviations ( $-2 \mathrm{SD}$ ) from the median of the reference population are considered as stunted children. The same criterion was applied by considering WHZ to identify the wasted children. Apart from these WAZ is a composite index of HAZ \& WHZ. It takes into account both acute $\&$ chronic undernutrition. After calculating the composite index, children whose WAZ is below minus two standard deviations $(-2 \mathrm{SD})$ from the median of the reference population are considered as an underweight children. In this present study, we have not directly measured children's stunting, wasting and underweight status from the raw dataset but we extracted data about child growth failure indices from NFHS district level fact sheets (NFHS-4, 2015-2016 \& NFHS-5, 2019-2020).

\subsection{Data analysis}

This evidence update study is primarily based on the data provided in the district level fact sheets published by NFHS, India. This article explores the major achievements and shortcomings on progress made on key indicators related to the nutritional status of Under- 5 children in the last 5 years (2015-2016 to 2019-2020) by making a comparative 
analysis from district level NFHS-4 factsheets and NFHS-5 factsheets of West Bengal state. District wise change detection of each child growth failure indices was estimated by differencing the previous round prevalence (NFHS-4) from current round prevalence (NFHS-5). Thematic mapping technique is used to show the current prevalence of each child growth failure indices in different districts of West Bengal.

\section{Results}

\subsection{Change detection of stunted children in different districts of West Bengal}

According to NFHS fact sheets, a steadily increasing trend of stunted or acutely undernourished children has been observed among 7 districts (Darjeeling [5.2\%], Kolkata [5.4\%], Maldah [2.7\%], Nadia [2.8\%], North 24 Pargana [8.6\%], South 24 Pargana [9.4\%] and Uttar Dinajpur [4.4\%]) of West Bengal (Table 1). Puruliya and Haoora are the two bestperforming states where a maximum declining trend (more than $7 \%$ ) have been observed between NFHS-4 (2015-2016) round andthe NFHS5 (2019-2020) round. On the other hand, Dakshin Dinajpur and Hugli are two worst-performing states where a very least declining trend (almost 1\%) has been observed. However, there have 12 districts in West Bengal that have minimized their proportion of stunted children in the 5 th round of NFHS from the 4th round of NFHS but North 24 Pargana \& South 24 Pargana are two districts of West Bengal where maximum increasing trend (more than 8\%) of acutely undernourished children has been identified.

\subsection{Change detection of wasted children in different districts of West Bengal}

Data shown in Table 2 indicates that the prevalence of wasting in Under 5 children has increased among 10 districts (Dakshin Dinajpur [5.7\%], Darjeeling [9.3\%], Haoora [6.7\%], Hugli [1.5\%], Jalpaiguri [0.6\%], Kolkatta [11.9\%], Nadia [6.9\%], Bardhaman [2.5\%], South 24 Pargana[1.1\%] and Uttar Dinajpur [2\%]) of West Bengal since 2015-2016 to 2019-2020. Puruliya is the only best performing district of West Bengal where a maximum declining trend in terms of wasting (almost 10\%) has been observed between the NFHS-4 (2015-2016) round and NFHS-5 (2019-2020) round. On the other hand, North 24 Pargana, Bankura and Murshidabad are the three worst-performing districts where a very least declining trend (almost 1\%) has been

Table 1

District wise change detection in prevalence of stunted children, West Bengal.

\begin{tabular}{llll}
\hline \multirow{2}{*}{ Districts of West Bengal } & \multicolumn{2}{l}{ NFHS ROUND } & \multirow{2}{*}{ Changes in \% } \\
\cline { 2 - 3 } & NFHS-4 & NFHS-5 & \\
\hline Bankura & 34 & 30.3 & -3.7 \\
Birbhum & 40.5 & 37 & -3.5 \\
Dakshin Dinajpur & 32.9 & 31.9 & -1.0 \\
Haoora & 34.6 & 27.5 & -7.1 \\
Hugli & 30.1 & 28.9 & -1.2 \\
Jalpaiguri & 31.2 & 28.9 & -2.3 \\
Koochbehar & 32.9 & 28.7 & -4.2 \\
Murshidabad & 41.9 & 39.8 & -2.1 \\
Barddhaman & 32.5 & 36.2 & -3.7 \\
PurbaMedinipur & 29.9 & 25.8 & -4.1 \\
PaschimMedinipur & 29.4 & 31.1 & -1.7 \\
Puruliya & 45.5 & 36.9 & -8.6 \\
Darjeeling & 29.1 & 34.3 & 5.2 \\
Kolkata & 24.2 & 29.6 & 5.4 \\
Maldah & 37.8 & 40.5 & 2.7 \\
Nadia & 23.3 & 26.1 & 2.8 \\
North 24 Pargana & 23.8 & 32.4 & 8.6 \\
South 24 Pargana & 27.3 & 36.7 & 9.4 \\
Uttar Dinajpur & 40.4 & 44.8 & 4.4 \\
\hline
\end{tabular}

Source: District fact sheets published by National Family Health Survey, India. (NFHS-4, 2015-2016 \& NFHS-5, 2019-2020, West Bengal).
Table 2

District wise change detection in prevalence of wasted children, West Bengal.

\begin{tabular}{llll}
\hline \multirow{2}{*}{ Districts of West Bengal } & \multicolumn{2}{l}{ NFHS ROUND } & Changes in \% \\
\cline { 2 - 3 } & NFHS-4 & NFHS-5 & \\
\hline Bankura & 27 & 26 & -1 \\
Birbhum & 29.5 & 25.5 & -4 \\
Koochbehar & 20.1 & 16.8 & -3.3 \\
Maldah & 22.8 & 20 & -2.8 \\
Murshidabad & 17.5 & 16.3 & -1.2 \\
North 24 Pargana & 13.6 & 13.3 & -0.3 \\
PurbaMedinipur & 24.5 & 15.5 & -9 \\
PaschimMedinipur & 28 & 30.3 & -2.3 \\
Puruliya & 34.6 & 29.4 & -5.2 \\
DaksinDinajpur & 17.1 & 22.8 & 5.7 \\
Darjeeling & 11.3 & 20.6 & 9.3 \\
Haoora & 14.6 & 21.3 & 6.7 \\
Hugli & 18.5 & 20 & 1.5 \\
Jalpaiguri & 17.7 & 18.3 & 0.6 \\
Kolkata & 17.4 & 29.3 & 11.9 \\
Nadia & 10.7 & 17.6 & 6.9 \\
Bardhhaman & 25.8 & 23.3 & 2.5 \\
South 24 Pargana & 20.1 & 21.2 & 1.1 \\
Uttar Dinajpur & 14 & 16 & 2 \\
\hline
\end{tabular}

Source: District fact sheets published by National Family Health Survey, India. (NFHS-4, 2015-2016 \& NFHS-5, 2019-2020, West Bengal).

observed over the same time period. Although, there were 9 districts in West Bengal who had minimized their proportion of wasted children in the 5 th round of NFHS from the 4th round of NFHS but Kolkata (Almost $12 \%$ ) and Darjeeling (Almost 10\%) are two districts of West Bengal where the maximum increasing trend of thinness or wasted children has been identified.

\subsection{Change detection of underweight children in different districts of West Bengal}

Table 3 delineates the weighted prevalence of underweight children in different districts of West Bengal. Although the proportions of underweight children (Under -5) were increased among 9 districts (Dakshin Dinajpur [2.1\%], Darjeeling [5.9\%], Hugli [4.7\%], Jalpaiguri [0.8\%], Kolkata [13.3\%], Nadia [5.8\%], North 24 Pargana [5.3\%], PaschimMedinipur [0.3\%] and South 24 Pargana [4.4\%]) of west Bengal since $2015-2016$ to $2019-2020$ but rests of the districts were able to

Table 3

District wise change detection in prevalence of underweight children, West Bengal.

\begin{tabular}{llll}
\hline \multirow{2}{*}{ Districts of West Bengal } & \multicolumn{2}{l}{ NFHS ROUND } & Changes in \% \\
\cline { 2 - 3 } & NFHS-4 & NFHS-5 & \\
\hline Bakura & 39.8 & 38.8 & -1 \\
Birbhum & 43.1 & 41.8 & -1.3 \\
Haoora & 28.4 & 27.3 & -1.1 \\
Koochbehar & 29.3 & 22.5 & -6.8 \\
Maldah & 37.2 & 35.3 & -1.9 \\
Murshidabad & 34.6 & 32.4 & -2.2 \\
Bardhhaman & 33.7 & 36.3 & -2.6 \\
PurbaMedinipur & 32.8 & 30.6 & -2.2 \\
Puruliya & 58.2 & 46.3 & -11.9 \\
Uttar Dinajpur & 34.7 & 32 & -2.7 \\
DaksinDinajpur & 28.1 & 30.2 & 2.1 \\
Darjeeling & 25.7 & 31.6 & 5.9 \\
Hugli & 28.7 & 33.4 & 4.7 \\
Jalpaiguri & 24.6 & 25.4 & 0.8 \\
Kolkata & 19.6 & 32.9 & 13.3 \\
Nadia & 19.3 & 25.1 & 5.8 \\
North 24 Pargana & 18.3 & 23.6 & 5.3 \\
PaschimMedinipur & 40.3 & 40 & 0.3 \\
South 24 Pargana & 27.8 & 32.2 & 4.4 \\
\hline
\end{tabular}

Source: District fact sheets published by National Family Health Survey, India. (NFHS-4, 2015-2016 \& NFHS-5, 2019-2020, West Bengal). 
decrease the proportion of underweight children. Interestingly, a maximum increasing trend (13.3\%) of underweight children is observed in Kolkata, the capital of West Bengal from NFHS-4 to NFHS-5 round. Puruliya is the only best performing district of West Bengal where the declining trend (11.9\%) of underweight children was observed maximum. In comparison among the three children's growth failure indices, the declining trend of underweight prevalence among Under 5 children was slightly low in different districts of West Bengal who were performed better in the NFHS 5th series.

\subsection{The current prevalence (2019-2020) of stunted childrenin different districts of West Bengal}

Currently, in West Bengal, 34\% of children below 5 years of age are suffering from stunting or acutely undernourished condition. Prevalence stunting status among Under 5 children in West Bengal has changed since 2015-2016. As per the state level NFHS report (2019-2020), the proportion of Under 5 children who are stunted increased slightly from $33 \%$ to $34 \%$ between the last two consecutive NFHS rounds across the state of West Bengal. The prevalence of stunted children in West Bengal (Fig. 1) varies from $25.8 \%$ in Purba Medinipur to $44.8 \%$ in Uttar Dinajpur. There were 2 high prevalence districts (Uttar Dinajpur [44.8\%] and Maldha [40.5\%]) in West Bengal where the proportion of stunted children is more than $40 \%$. There were only 6 less prevalence districts (Haoora [27.5\%], Hugli [28.9\%], Jalpaiguri [28.9\%], Purba Medinipur [25.8\%], Kolkata [29.6\%] and Nadia [26.1\%]) in West Bengal where the proportion of stunted children is comparative less i.e., $30 \%$. Rest of the districts of West Bengal comes under moderately prevalent districts where the weighted proportion of stunted children varies in between $30 \%$ and $40 \%$.
3.5. The current prevalence (2019-2020) of wasted children in different districts of West Bengal

Fig. 2 displays the current weighted prevalence of wasted children below 5 years of age for all the districts of West Bengal. Though the weighted prevalence of wasted children remains unchanged (20\%) from 2015 to 2016 (NFHS-4) to 2019-2020 (NFHS-5) across the state but the proportion varies among districts. The weighted proportion of wasted children (too thin for their height) varies from the highest in Paschim Medinipur (30.3\%) to the lowest in North 24 Pargana (13.3\%). Three districts (Paschim Medinipur [30.3\%], Purulia [29.4\%] and Kolkatta [29.3\%]) of the state are the worst sufferer from wasting. There have only 7 districts (Koochbehar [16.8\%], Murshidabad [16.3\%], North 24 Pargana [13.3\%], Purba Medinipur [15.5\%], Jalpaiguri [18.3\%], Nadia [17.6\%], Uttar Dinajpur [16\%]) in West Bengal who were less sufferer from thinness than the state average (20\%) while the prevalence of wasted children was moderate in rest of the districts of West Bengal. An interesting fact is that the state capital of West Bengal has also failed to minimize the proportion of thinness among Under 5 children where a substantial proportion of wasted children (11.9\%) has increased in the latest round of NFHS (2019-2020) from the previous round (Table 2).

\subsection{The current prevalence (2019-2020) of underweight children in different districts of West Bengal}

Fig. 3 represents the current spatial distribution of underweight children in different districts of West Bengal. Like wasted children, the weighted prevalence of underweight children is also remained unchanged (32\%) from 2015 to 2016 (NFHS-4) to 2019-2020 (NFHS-5) across the state but the proportion varies among districts. The weighted proportion of underweight children (low weight for age) varies from the highest in Puruliya (46.3\%) to the lowest in Koochbehar (22.5\%).There were 2 high prevalence districts (Puruliya [46.3\%] and Birbhum

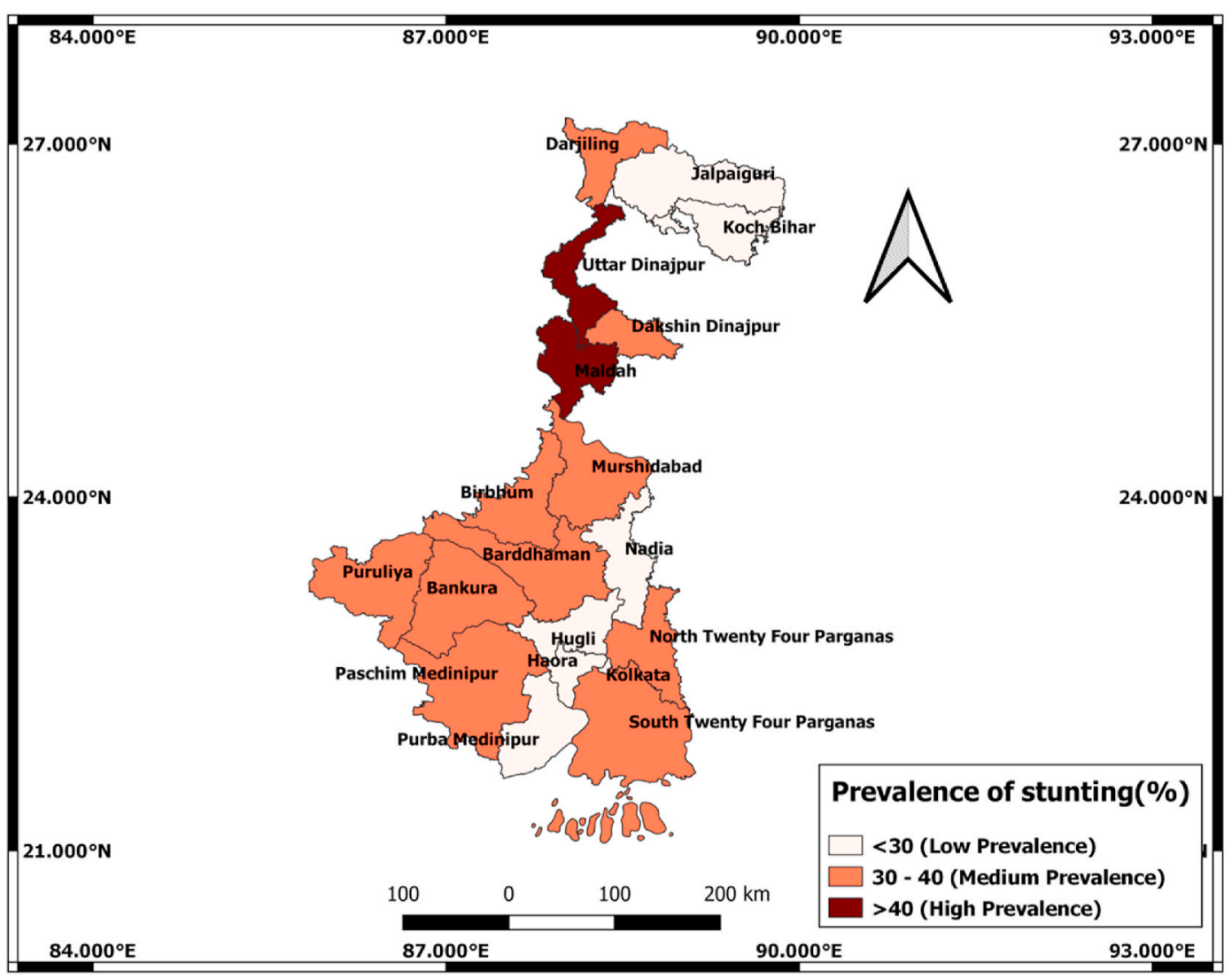

Fig. 1. Prevalence of stunted children in different districts of West Bengal, India, 2019-2020. 


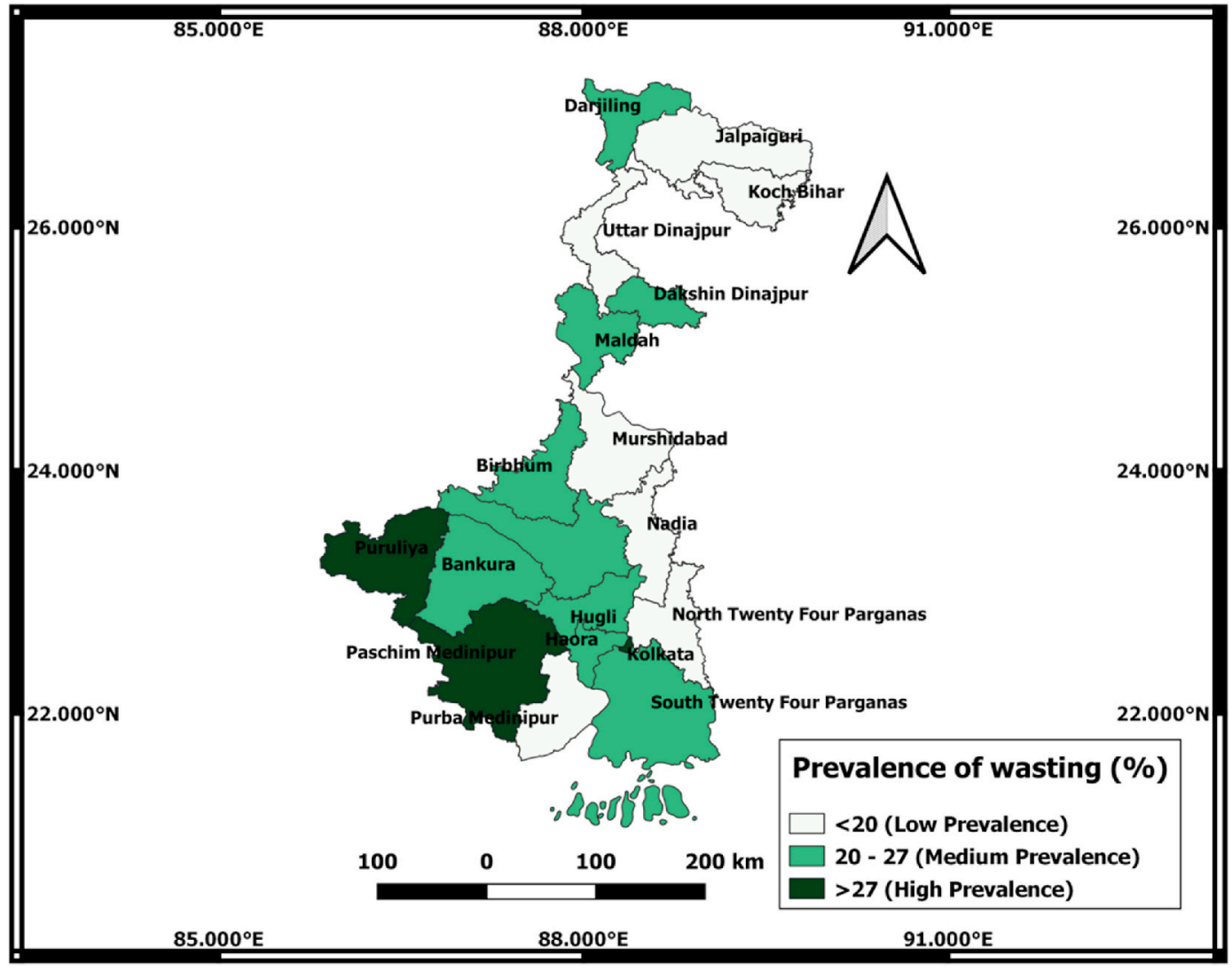

Fig. 2. Prevalence of wasted children in different districts of West Bengal, India, 2019-2020.

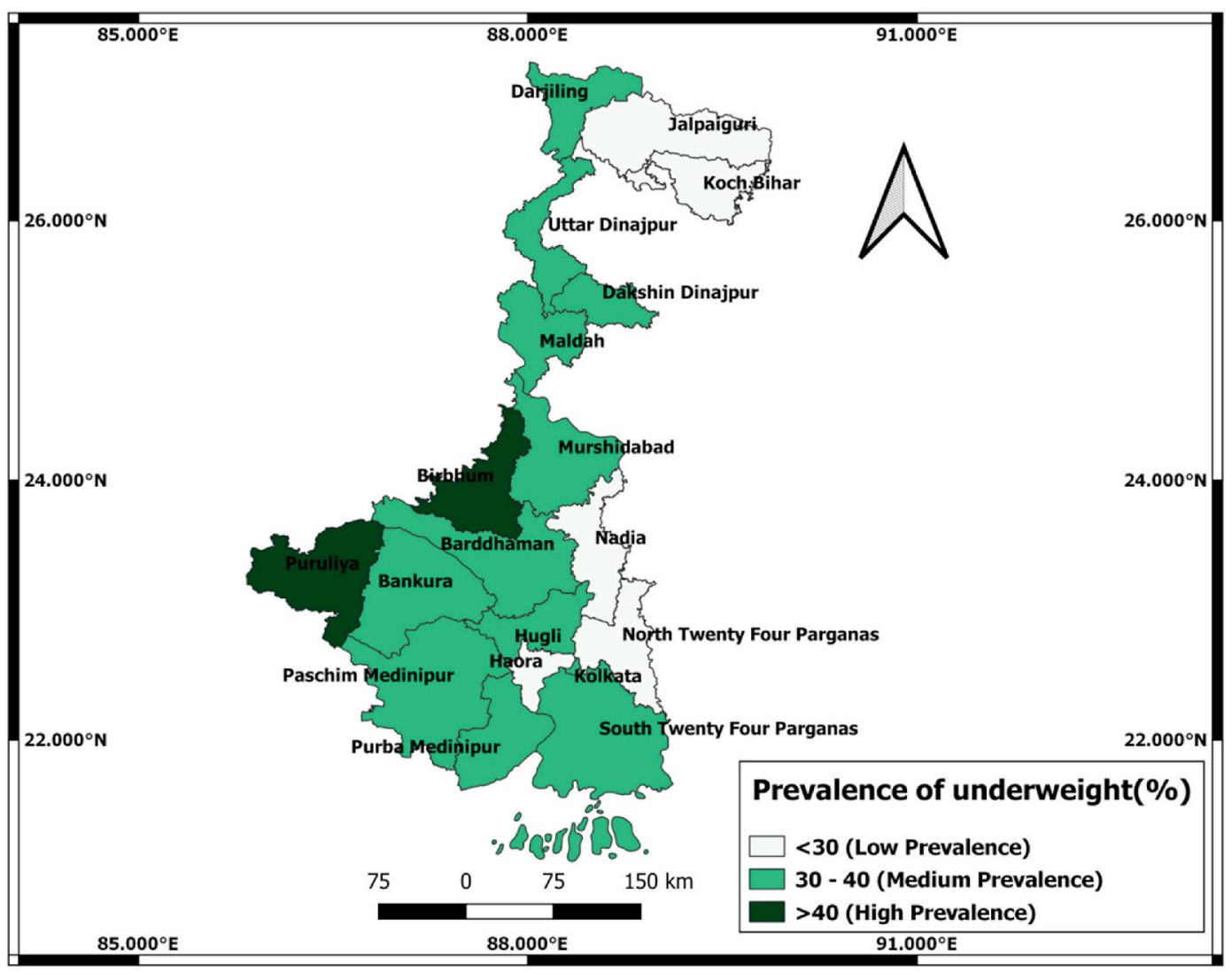

Fig. 3. Prevalence of underweight children in different districts of West Bengal, India, 2019-2020. 
[41.8\%]) in West Bengal where the proportion of stunted children is more than 40\%. Only 5 districts (Koochbehar [22.5\%], North 24 Pargana [23.6\%], Nadia [25.1\%], Jalpaiguri [25.4\%] and Haoora [27.3\%]) are there where the weighted prevalence of underweight children is less than $30 \%$. Apart from high and less prevalence districts, the rest of the districts of West Bengal are moderately suffered from underweight conditions among children age Under 5 years. Interestingly, Kolkata the state capital of West Bengal is also failed to decrease the underweight condition among Under 5-year children where a substantial proportion of wasted children (13.3\%) has increased in the latest round of NFHS (2019-2020) from the previous round (Table 2).

\section{Discussion}

This study provides information about the prevalence of child growth failure indices (stunting, wasting and underweight) in different districts of West Bengal. Furthermore, district wise change detection of each child growth failure measurement is also measured in this present evidence base study. The data revealed that there were 13 high priority districts (Darjeeling, Kolkata, Maldha, Nadia, North 24 Pargana, South 24 Pargana, Uttar Dinajpur, Dakshin Dinajpur, Haoora, Hugli, Jalpaiguri, Bardhaman, PaschimMedinipur) in West Bengal where at least one child growth failure measurement (stunting/wasting/underweight) is marginally or hardly increased in 2019-2020 from 2015 to 2016. Total 6 hotspot districts were identified in West Bengal where the current prevalence of stunted (Uttar Dinajpur, Maldah), wasted (PaschimMedinipur, Puruliya and Kolkata) and underweight (Puruliya and Birbhum) children is maximum. So, first of all, we have to give special attention on those six high prevalence districts to minimize children's undernutrition condition. As shown in various previous studies low or very less parental educational attainment, poor household living condition, parental unemployment situation, less attention on maternal antenatal \& postnatal care, child marriage, mother's under nutrition condition, poor maternal and child's dietary diversity, poor immunization coverage among children are strongly and positively associated with child growth failure incidents. ${ }^{35-39}$ As per Census 2011 West Bengal is the fourth populous state of India (after Uttar Pradesh, Maharashtra, Bihar) with a population density $1029 / \mathrm{KM}^{2}$ which is much higher than the national average (382/Sq. Km). Literacy differential exists among different districts of West Bengal. ${ }^{40}$ In addition there are wide range of gaps between male and female literacy; rural and urban literacy; rural male \& female literacy; urban male \& female literacy etc. These were some possible reasons that all the districts are not uniquely able to minimize their undernutritional condition among children below 5 years of age. On the other hand it is fully acceptable that education directly correlated with unemployment, poverty, child marriage etc. and these also some motivating factors behind the growth faltering incidents. One study from West Bengal estimated that child immunization coverage has not done uniquely across the state and resulted that Uttar Dinajpur and Murshidabad are two least child immunization coverage districts. ${ }^{41}$ Moreover, West Bengal is multi-ethnic and is the home to geographically diverse population and very diverse economic groups (poorest, poorer, middle, richer and richest) which may be one possible reasons for the uneven progression in reducing child growth failure phenomena among districts. On one hand, health service indicators like Under 5 mortality rate, vaccination coverage, child immunization coverage get improvement in West Bengal but latest NFHS (NFHS-5) round shows worsening of under nutrition among children while we have to acknowledge that under nutrition is a serious child health problem across state but the data does not provide any causes for the risen of under nutrition condition among children at present. We need micro level data to understand the causes behind this. Various health schemes have been implemented over the last few years by the state and central government to improve child health status; however, there is a need to modify strategies to achieve best health outcomes. Overall development across the state in subject to socio-economic, political, environmental is required urgent basis to improve child health status.

\section{Conclusions \& recommendations}

Child growth failure is an indication of malnutrition and children below 5 years of age is a nutritionally more vulnerable group. It is already proved that most of the malnutrient children are unable to grow their full potential on physical and mental health. Results of this present evidence base study revealed that there were several districts in West Bengal where the current prevalence of nutritional measurements namely stunting (height-for-age), wasting (weight-for-height) and underweight (weight-for-age) were higher than the state average as well as the national average. Furthermore, this study also found a marginal increasing trend in nutritional measurements in several districts of West Bengal rather than decreasing trend and currently it is a serious matter of concern for child health wellbeing. Overall scrutiny on current nutritional schemes and state-specific as well as district-specific auspicious, relevant \& immediate renewed nutritional interventions are required to flourish the crux of child growth failure phenomena in terms of malnutrition. Here we have given some strategies that may help the local government and policymakers to take initiatives for mitigating the child growth failure phenomena.

- As the prevalence of child nutritional measurements is still very high in different districts of West Bengal, there are no alternatives that may ignore this problem. Therefore, to minimize the burden of malnutrition among children Under 5 , a joint effort by the government, NGOs and the community are just needed to improve the nutritional status of the children along with mothers' health.

- To improve the overall nutritional status of children Under 5 year government may have to design renewed intervention programs/ strategies by targeting the vulnerable groups of people in the society.

- Initiatives have to take for accessing the health care information through all kinds of media is to be engaged with the rural community, urban slum community, etc.

- Proper implementation of Integrated Child Development Services Scheme (ICDS) in rural and urban slums areas is very much urgent across the state of West Bengal.

- More specific interventions such as improvement in parental education, wealth conditions etc. are needed to be addressed to diminishing the aforesaid child growth failure problem.

\section{Funding information}

This research did not receive any specific grant from funding agencies in the public, commercial, or not-for-profit sectors.

\section{Ethical statement}

The study is based on a secondary data set from the recent NFHS-4 survey with no identifiable information on the survey participants. NFHS- 4 obtained the consent before and during the survey. This dataset is available in the public domain for research use and, hence, no ethical approval was needed specifically for the present study. The data can be freely accessed from the NFHS website at http://rchiips.org/nfhs/

\section{Funding}

This research received no grant or funding from any funding agency.

\section{Declaration of competing interest}

Authors hereby declare that there are no conflicts of interest. 


\section{Acknowledgements}

All authors have read and approved the final manuscript.

\section{References}

1 Rahman A, Rahman MS, Rahman MA. Determinants of infant mortality in Bangladesh: a nationally surveyed data analysis. International Journal of Child Health and Nutrition. 2019 Aug 31;8(3):93-102.

2 Rahman A, Biswas SC. Nutritional status of under-5 children in Bangladesh. South Asian Journal of Population and Health. 2009;2(1), 1-1.

3 Rahman A, \&Rahman MS. Rural-urban differentials of childhood malnutrition in Bangladesh. International Journal of Child Health and Nutrition. 2019;8(1):35-42.

4 Mengistu K, Alemu K, Destaw B. Prevalence of malnutrition and associated factors among children aged 6-59 months at HidabuAbote district, north shewa, oromia regional state. $J$ nutr disorders ther. 2013;1:1-5.

5 Aurangzeb B, Whitten KE, Harrison B, et al. Prevalence of malnutrition and risk of under-nutrition in hospitalized children. Clinical nutrition. 2012 Feb 1;31(1):35-40.

6 Aurangzeb B, Whitten KE, Harrison B, et al. Prevalence of malnutrition and risk of under-nutrition in hospitalized children. Clinical nutrition. 2012 Feb 1;31(1):35-40.

7 Hakim MA, Rahman A. Health and nutritional condition of street children of Dhaka city: an empirical study in Bangladesh. Science Journal of Public Health. 2016;4(1-1): $6-9$.

8 Black RE, Victora CG, Walker SP, et al. Maternal and child undernutrition and overweight in low-income and middle-income countries. The lancet. 2013 Aug 3;382 (9890):427-451.

9 Black RE, Allen LH, Bhutta ZA, et al. Maternal and child undernutrition: global and regional exposures and health consequences. The lancet. 2008 Jan 19;371(9608): 243-260.

10 Khan J, Mohanty SK. Spatial heterogeneity and correlates of child malnutrition in districts of India. BMC public health. 2018 Dec;18(1):1-3.

11 World Health Organization Health. From MDGs, Millennium Development Goals to SDGs, Sustainable Development Goals. 2015.

12 Unicef. Improving Child Nutrition: The Achievable Imperative for Global Progress. New York: UNICEF; 2013 Apr 1:1-4.

13 National Family Health Survey (NFHS-5). International Institute for Population Sciences (IIPS) and ICF. India. Mumbai: IIPS; 2020. Extracted from http://rchiips.org/nfhs/.

14 Wachs TD. Multiple influences on children's nutritional deficiencies: a systems perspective. Physiology \& Behavior. 2008 Apr 22;94(1):48-60.

15 Silva P. Environmental Factors and Children's Malnutrition in Ethiopia. Available at SSRN 648038. 2005.

16 Wachs TD, Creed-Kanashiro H, Cueto S, Jacoby E. Maternal education and intelligence predict offspring diet and nutritional status. The Journal of nutrition. 2005 Sep 1;135(9):2179-2186.

17 Kumar D, Goel NK, Mittal PC, Misra P. Influence of infant-feeding practices on nutritional status of under-five children. The Indian Journal of Pediatrics. 2006 May; 73(5):417-421.

18 Engebretsen IM, Tylleskär T, Wamani H, Karamagi C, Tumwine JK. Determinants of infant growth in Eastern Uganda: a community-based cross-sectional study. BMC public health. 2008 Dec;8(1):1-2.

19 Getahun Z, Urga K, Ganebo T, Nigatu A. Review of the status of malnutrition and trends in Ethiopia. The Ethiopian Journal of Health Development. 2001;15(2).

20 Das S, Sahoo H. An investigation into factors affecting child undernutrition in Madhya Pradesh. The Anthropologist. 2011 Jul 1;13(3):227-233.

21 Black RE, Victora CG, Walker SP, et al. Maternal and child undernutrition and overweight in low-income and middle-income countries. The lancet. 2013 Aug 3;382 (9890):427-451.
22 Nandy S, Irving M, Gordon D, Subramanian SV, Smith GD. Poverty, child undernutrition and morbidity: new evidence from India. Bulletin of the World Health Organization. 2005;83:210-216.

23 Subramanyam MA, Kawachi I, Berkman LF, Subramanian SV. Is economic growth associated with reduction in child undernutrition in India? PLoS medicine. 2011 Mar 8;8(3), e1000424.

24 Mahgoub SE, Nnyepi M, Bandeke T. Factors affecting prevalence of malnutrition among children under three years of age in Botswana. African Journal of Food, Agriculture, Nutrition and Development. 2006;6(1).

25 Nguyen PH, Saha KK, Ali D, et al. Maternal mental health is associated with child undernutrition and illness in Bangladesh, Vietnam and Ethiopia. Public health nutrition. 2014 Jun;17(6):1318-1327.

26 Tadesse S, Alemu Y. Urban-rural differentials in child undernutrition in Ethiopia. International Journal of Nutrition and Metabolism. 2015 Jan 31;7(1):15-23.

27 Shroff M, Griffiths P, Adair L, Suchindran C, Bentley M. Maternal autonomy is inversely related to child stunting in Andhra Pradesh, India. Maternal \& child nutrition. 2009 Jan;5(1):64-74.

28 Christiaensen L, Alderman H. Child malnutrition in Ethiopia: can maternal knowledge augment the role of income? Economic Development and cultural change. 2004 Jan;52(2):287-312.

29 Nguyen PH, Scott S, Neupane S, Tran LM, Menon P. Social, biological, and programmatic factors linking adolescent pregnancy and early childhood undernutrition: a path analysis of India's 2016 National Family and Health Survey. The Lancet Child \& Adolescent Health. 2019 Jul 1;3(7):463-473.

30 Bhattacharya G, Haldar SK. Trend, differential and determinants of deprivation of reproductive and child health in the districts of West Bengal, India. Journal of Health Management. 2014 Mar;16(1):93-112.

31 Biswas B. Regional disparities pattern of literacy in rural and urban area of West Bengal, India. Global Journal of Multidisciplinary Studies. 2016;5(7):105-112.

32 Planning Commission. West Bengal Development Report. 2010.

33 Islam MS, Siddiqui L. A geographical analysis of gender inequality in literacy among Muslims of West Bengal, India (2001-2011). GeoJournal. 2020 Oct;85(5): $1325-1354$.

34 Chandra H. District-level estimates of poverty incidence for the state of West Bengal in India: application of small area estimation technique combining NSSO survey and Census data. Journal of Quantitative Economics. 2021 Jan 15:1-7.

35 Hong R, Banta JE, Betancourt JA. Relationship between household wealth inequality and chronic childhood under-nutrition in Bangladesh. International journal for equity in health. 2006 Dec;5(1), 1-0.

36 Parsons CE, Young KS, Rochat TJ, Kringelbach ML, Stein A. Postnatal depression and its effects on child development: a review of evidence from low-and middle-income countries. British medical bulletin. 2012 Mar 1;101(1):57-79.

37 McDonald CM, McLean J, Kroeun H, Talukder A, Lynd LD, Green TJ. Household food insecurity and dietary diversity as correlates of maternal and child undernutrition in rural Cambodia. European Journal of Clinical Nutrition. 2015 Feb;69(2):242-246.

38 Owoaje E, Onifade O, Desmennu A. Family and socioeconomic risk factors for undernutrition among children aged 6 to 23 Months in Ibadan, Nigeria. The Pan African medical journal. 2014;17.

39 Vir SC, Adhikari T, Pandey A, Nigam AK, Malik R. Child undernutrition in India: agewise trend and risk factors. Statistics and Application. 2015 Jan 1;13:85-93.

40 Som KS, Mishra RP. Literacy and their differential in West Bengal. International Journal of Science and Research. 2014;3(6):1537-1545.

41 Som S, Pal M, Chakrabarty S, Bharati P. Socioeconomic impact on child immunisation in the districts of West Bengal, India. Singapore medical journal. 2010 May 1;51(5):406. 